\title{
Las Opiniones sacadas de los más auténticos y antigos philósofos que sobre la alma escrivieron y sus difiniciones, de Daniel Arón Afia
}

\author{
James W. Nelson Novoa* \\ Cátedra «Alberto Benveniste», Universidade de Lisboa
}

\begin{abstract}
Las Opiniones sacadas de los más auténticos y antigos philósofos que sobre la alma escrivieron y sus difiniciones fueron publicadas en 1568 en Venecia, junto con la primera traducción española de los Diálogos de amor de León Hebreo. Escritas por Daniel Arón Afia, profesor de latín y filosofía establecido en la Salónica de la segunda mitad del siglo XVI, este autor de familia conversa vuelta al judaísmo tras su establecimiento en tierras otomanas. El opúsculo de apenas doce folios es un compendio de definiciones del alma propuestas por pensadores, desde la Antigüedad hasta el Renacimiento, muestra de la actividad intelectual desarrollada en hebreo, latín y castellano de los conversos que escogieron la vía del exilio en el Levante mediterráneo. El volumen fue dedicado a Felipe II y muestra el apego de su promotor a la cultura hispánica.
\end{abstract}

Palabras ClaVE: Levante; alma; Renacimiento; humanismo; conversos.

THE OPINIONES SACADAS DE LOS MÁS AUTÉNTICOS Y ANTIGOS PHILÓSOFOS QUE SOBRE LA ALMA ESCRIVIERON Y SUS DIFINICIONES, By Daniel Aron AFIA.— Included in a volume published in 1568 in Venice alongside the first Spanish translation of Leon Hebreo's Diálogos de amor, the Opiniones sacadas de los más auténticos y antigos philósofos que sobre la alma escrivieron y sus difiniciones, were written by Aron Daniel Afia, an important Latin and Philosophy scholar in the Salonika of the second half of the $16^{\text {th }} \mathrm{c}$. Descendant of a Converso family returned to Judaism after settlement in Ottoman lands, his short twelve folio work is a compendium of definitions of the soul proposed by thinkers from Antiquity to Renaissance, being a precious example of the intellectual activity (in Latin, Spanish and Hebrew) of the Conversos who chose exile in the Levant. The volume, dedicated to Philip II, shows the attachment of former Conversos to Spanish culture.

KeYwords: Levant; Soul; Renaissance; Humanism; Conversos.

$\mathrm{Al}$ igual que ocurre con otros muchos autores, descendientes de las primeras oleadas del exilio sefardí que escogieron el mundo otomano como lugar de refugio, sabemos muy poco de Daniel Arón Afia. Es conocido sobre todo como autor de un opúsculo contenido en la edición veneciana de la primera traducción en lengua castellana impresa de los Diálogos de amor de León Hebreo (¿1460 - 1530?), titulado Opiniones sacadas de los más auténticos y antigos philósofos que sobre

\footnotetext{
*jw_nel@yahoo.com. Becario de la Fundação para a Ciência e a Tecnologia, Portugal.
} 
la alma escrivieron y sus difiniciones ${ }^{1}$. Aparte del interés intrínseco de este personaje por ser una figura de la cultura intelectual sefardí del siglo XVI, Afia y su obra merecen ser estudiados como reflejo de las relaciones entre la cultura judía y la cristiana durante el mismo período, sobre todo en el ámbito de las comunidades sefardíes del Levante, compuestas en gran parte por cristianos nuevos que decidieron abrazar abiertamente la fe judía.

Debido a las razones que expondremos ahora, la obra es excepcional y nos dice mucho sobre la realidad sociocultural de los conversos que eligieron el Levante para volver a la fe de sus padres y de su universo libresco y científico. Lejos de ser un mundo replegado sobre sí mismo, la cultura intelectual de los conversos vueltos al judaísmo en el Oriente refleja la realidad de los miembros de sus comunidades, formados en Europa e imbuidos de la cultura del momento que reflejaba los atisbos del Renacimiento. En el seno de las comunidades sefardíes confluían la cultura humanística, literaria y médica de las universidades europeas, el incipiente espíritu empírico y crítico, la gran tradición filosófica hispano-judía y la cultura rabínica. La obra de Afia refleja estas vertientes que coexistían en aquel mundo tan particular que fue el primer exilio converso del siglo XVI y las incipientes comunidades sefardíes en los dominios del sultán. Por su contenido, así como por las circunstancias y por el lugar de su aparición, creemos que refleja, en buena medida, la especificidad del ámbito social de los antiguos conversos en el Levante.

Lo poco que sabemos sobre este autor lo han recogido estudiosos de la cultura sefardí en el Imperio Otomano como Joseph Nehama e Isaac S. Emmanuel, o estudiosos de la cultura filosófica de los judíos del Renacimiento, como Cecil Roth y Henry Friedenwald. Los detalles en los que estos autores coinciden son los siguientes: Daniel Arón Afia (o Afius), al parecer, oriundo de la Península Ibérica, era uno de los que escogieron la vía del exilio en tierras otomanas. Ignoramos su fecha de nacimiento o aquélla en la que llegó a la Sublime Puerta. Friedenwald lo supone emparentado con la célebre familia Abulafia ${ }^{2}$. El erudito estudioso de la cultura ibérica Moritz Kayserling dice que ya alrededor de 1540 había destacado como médico, enseñante de latín, de astronomía y de filosofía, así como traductor en Salónica de obras filosóficas al hebreo ${ }^{3}$. El gran estudioso del ambiente sefardí

${ }^{1}$ Véase nuestra edición de la obra aparecida en 2005 en los Anexos de la revista electrónica Lemir (www.parnaseo.uv.es).

${ }^{2}$ H. Friedenwald, «Spanish and Portuguese Physicians after the Expulsion at the end of the Fifteenth Century», Jews and Medicine, vol. 2 (New York 1967, reimpr.), pág. 707.

${ }^{3}$ M. KaYserling, «Aron Afia», The Jewish Encyclopedia, vol. 1 (New York - London), pág. 224. 
de Salónica, Isaac S. Emmanuel lo denomina «el maestro de Salónica» de aquellos años ${ }^{4}$. Otro destacado historiador de la vida sefardí en la ciudad levantina, Joseph Nehama, celebró su cultura humanística y dijo que Afia había sido el «amigo inseparable» de Amato Lusitano y el maestro del conocido astrónomo Daniel Perahyá Hacohén (muerto en 1575), al que adjudica una sensibilidad impregnada de empirismo y ciencia ${ }^{5}$. Otro estudioso del mundo levantino, Isaac R. Molho, afirmó que fue maestro del salonicense Moisés Almosnino (1518-1580) ${ }^{6}$.

Su destreza en el manejo del latín ha hecho que todos los autores que lo han mencionado resaltaran su papel de traductor. Moritz Steinschneider nos da la noticia de que Afia había ayudado a Moisés Almosnino a traducir al hebreo la obra Theoricae novae planetarum del astrónomo Georg von Purbach (1423-1461) impresa en 1472, en la que su autor abraza el sistema tolomaico y que tuvo la distinción de contar entre los primeros libros impresos ${ }^{7}$. Asistió, además, a Almosnino con su obra Bet Elohim we-ša 'ar ha-šamayim, un comentario al Tractatus de sphaera del astrónomo y matemático inglés, Johannes de Sacrobosco (m. ca. 1256), que había tenido gran difusión y que sirvió de manual de astronomía durante la Edad Media y hasta el Renacimiento, contando entre sus fuentes a Tolomeo y a otros autores griegos, latinos y árabes. Parece, de hecho, que en este caso se trata de una obra compuesta en gran medida por Afia y casi dictada por él a Almosnino ${ }^{8}$. Para su comentario, Afia y Almosnino se sirvieron de la traducción hebrea de autor provenzal Salomón b. Abraham Avigdor ${ }^{9}$. Junto al médico Daniel Perahyá Hacohén, Afia tradujo al hebreo el Almanach Perpetuum del castellano Abraham Zacut, a partir del original latín en el que el texto había aparecido impreso por primera vez en 1496. Esta traducción se publicó en 1568 en Salónica, junto con un comentario titulado Šeerit Yosef $^{10}$.

${ }^{4}$ I. S. Emmanuel, Histoire des Israélites de Salonique (140 av. J. C. à 1640). Histoire sociale, économique et littéraire de la Ville Mère en Israël... (Paris 1936), pág. 204.

5 J. Nehama, Histoire des israélites de Salonique. III : L'âge d'or du Sefaradisme Salonicien (1536-1593). Premier fascicule (Paris 1936), pág. 159.

${ }^{6}$ I. R. MolHo, «Un humaniste séfardi de Salonique: Moïse Barouh Almosnino (1518-1581)», Tesoro de los judíos sefardíes 7 (1964), págs. 49-68, págs. 49-68: 52.

${ }^{7}$ M. SteinschneIDER, Die Hebräischen Übersetzungen des Mittelalters und die Juden als Dolmetscher (Berlin 1893), pág. 645.

${ }^{8}$ Según J. Hacker, «The Intellectual Activity of the Jews of the Ottoman Empire during the Sixteenth and Seventeenth Centuries», en Jewish Thought in the Seventeenth Century, eds. I. Twersky \& B. Septimus (Cambridge, MA 1987), págs. 95-135: 118.

9 SteinschneIder, Die Hebräischen Übersetzungen, págs. 643 y 645.

${ }^{10}$ HACKer, «The Intellectual Activity», pág. 118. 
Afia aparece mencionado en la vigésimo cuarta Curatio de la séptima Centuria del médico y filósofo João Rodrigues de Castelo Branco, más conocido como Amato Lusitano (1511-68), como interlocutor del autor de la obra que le califica de «doctorem Affium Philosophum peripateticum». Esta obra se compuso en torno a 1561 en Salónica, última morada del médico y humanista portugués ${ }^{11}$. En este texto ambos médicos mantienen un entretenido debate acerca de dónde se sitúa la fuente de la risa. Lusitano, citando a Hipócrates y a Plinio, insiste en situarla en el diafragma, mientras que Afia opta por la posición aristotélica que la situaba en el corazón ${ }^{12}$. El debate concluye con una alusión, por parte de Lusitano, a la plétora de obras acerca del alma, destacando, de modo particular, los tratados de Philipp Melanchton y Juan Luis Vives acerca del tema ${ }^{13}$. De hecho, alrededor de 1552 se había impreso en Zúrich un volumen que contenía tres tratados sobre el alma, de Vives, del bávaro Veit Amerbach (1503-57) y de Melanchton ${ }^{14}$. En el caso del tratado del humanista

${ }_{11}$ Amati Lusitani, Medici Physici Praestantissimi, Curationum medicinalium. Centuria Septima. Thessalonicae curationes habitas continens varia multiplicique doctrina referta. Accesit Index rerum memorabilium copiosissimus (Lugduni 1570). «Curatio vigesimaquarta, in qua docetur, septum transversum risus sive hilaritatis sedem esse, ad doctorem Affium Philosophum peripateticum», fols. 68-74. Lusitano especifica que su séptima y última Centuria fue terminada en «Thessalonicae, mense Augusto, anno a mundo creato, 5321 secundum vero computum Romanum, 1561».

12 «Saepe in dubium verti, docte Affi, an Plinius recte senserit, cum praecordia, hoc est, septum transversum, Greci, phrenas, vel diaphragma et ano coilian appelare solent, risus sedem interiorem fecerit. Affius. Absit ut verum hoc credamus, immo peripatetici magistri nostri in corde facultatem hanc, velut plures alias, collocari, nos docuerunt. Missos hic facio sordidulos magistellos, quorum doctrinam explosam, diu est, habeo, qui Salmancicae carminibus quibusdam, suo iure compositis, lienem risus fontem statuebat. Sed ubi nam Plinius haec tradat, aut quibus rationibus fulciatur, aperi rogo. Amatus. Haec cum non omnibus pervia sint, lubenter faciam audi igitur Plinius libro xj. Nat suae Hist. C. 37 inquit, Praecordia iquod illi septum transversum, ut dixi est! risus et hilaritatis sedes sunt, quod rationibus et experimento probat, quia ita nervosa haec cernitur pars, ut ei merito debeat referri, non solum mentis subtilitas, sed ingenii acuitas; unde forte Graeci, phrenas appellaverunt...», fols. 68-69. En el debate entre los dos pensadores sefardíes, Lusitano se apoya en la posición de Plinio el Viejo en el undécimo libro de su Naturalis historia, donde defiende la tesis del diafragma (praecordia), que se encuentra delante del corazón, como el órgano de donde procede la risa y el ingenio, en contra del peripatético Afia, que la sitúa en el corazón (corde).

13 «Caeterum, de risu, multa et pulchra philosophis petite, Libri de anima quos nostro hoc tempore Philippus Melanthon Germanus sapientissime scripsit et Vives Valentinus acutissime absolvit», f. 74 .

${ }^{14}$ Ioannis Lodovici Vivis Valentini, De anima et vita libri tres. Riusdem argumenti. Viti Amerbachil, De anima libri III. Philippi Melanthonis, Liber unus. Hic accedit nunc primum. Conradi Generi de anima liber, sentenziosa brevitate, velutique per tabula set aphorismos magna 
valenciano de padres conversos exiliado en los Países Bajos, se trataba de una reedición, pues la editio princeps había aparecido en Basilea en $1538{ }^{15}$. El humanista y reformador alemán Melanchton, sobrino de Johannes Reuchlin, había compuesto su tratado en 1540 y lo había publicado por primera vez en Estrasburgo en $1544^{16}$. En su tratado, Vives dedica un capítulo entero al tema de la risa, citando a Plinio y compartiendo el punto de vista de Lusitano expuesto en su séptima Centuria ${ }^{17}$.

Pero sin lugar a dudas el nombre de Afia es más conocido como autor del opúsculo filosófico las Opiniones sacadas de los más auténticos y antigos philósofos que sobre el alma escrivieron y sus difiniciones. Por el piritíssimo doctor Arón Afia, Philósofo y Metafísico excelentíssimo. Con diligencia y brevedad admirable a común utilidad de los curiosos de venir en conocimiento de tan ardua materia, obra impresa en Venecia en 1568 junto con la primera traducción en lengua castellana impresa de los Diálogos de amor del médico y filósofo criado en Portugal, formado en Castilla y luego exiliado en Italia, León Hebreo, publicado por primera vez en lengua italiana en Roma en $1535^{18}$.

ex parte conscriptus, philosophiae, rei medicae ac philologiae studiosis accomodatus: in quo de tactilibus qualitatibus, saporibus, odoribus, soni set coloribus, copiose accurateque tractatur.

${ }^{15}$ Ionnis Lodovici VIvis Valentini, De anima et vita libri tres. Opus insigne, nunc primum in lucem editum. Rerum et verborum in isdem memorabilium copiosissimus Index. Cum gratia et privilegio ad triennium (Basileae 1538).

16 Philippi Melanthonis, Commentarius de anima (Argentorati 1544).

17 «Ex laetitia et delectatione risus nascitur, qui affectus non est sed actio exterior ab interior manans. Nam ex laetitia vel delectatione dilatatur cor, ad cuius motum et facies extenditur, eaque potissimum pars, quae est circa os, qui rictus nominatur, unde risus. Itaque risus exteriorem sedem habet in rictu primum hinc in oculis et cuncto vultu. Interiorem, autem, Plinius Secundus affirmat esse in praecordis, quas Graeci $\varphi \rho \varepsilon v \alpha \varsigma$ appelant. In his inquit, praecipua hilari satis sedes, quod titillatu maxime deprehenditur alarum, quas subit et gladiatores, qui eo loci essent fauciati, ridentes oppetiisse. Qui risus corporalis est prorsus, non ex affectum sicut in titillatione sub axillis, aut aliis in locis et ego ad primam et alteram buccam, quam summo a longa inedia, non possum risum continere: videlicet contracta praecordia dilatatur ex cibo. Nec risus ille est verus in moerore, aut indignatione qualem fuisse Hannibalis in curia Carthaginensi ferunt, victi a Scipione, ringere enim est illud, non ridere. In quibus flaura abundat bilis, ii ad risum sunt proni, quod ex calore immodico facile exporrigitur cor: sicut rursum frigoris lenti sunt ad ridendum. Risus qui ex affectu nascitur, de laetitia est, aut delectatione nova. Surgit enim primo illo contacto, quo laetitia vel delectatio recens movet animum. Insperata vero et subita plus afficiunt, citius commovent risum et maiorem», De anima et vita, liber III (ed. 1538), fols. 201-202. Según Vives la risa tiene su origen en la alegría (laetitia) y la delectación (delectatione), que son movimientos del alma, manifestándose a través de una dilatación del corazón y de la boca.

${ }_{18}$ Dialoghi d'amore di Leone Medico Hebreo. Stampato per Antonio Blado d'Assola del M.D.XXXV. 
La obra de Afia ocupa doce folios (116r-127r) y su contenido cumple fielmente con lo prometido en el título. Se trata, en efecto, de un compendio de definiciones del alma y de su naturaleza, recogidas desde los pensadores de la Antigüedad hasta las de sus coetáneos. Afia comienza su tratado con estas palabras, anunciando su propósito y desde el inicio, mostrándose deudor de Aristóteles y destacando la dificultad del asunto tratado:

Muy difícil se hizo a los antiguos hablar en la alma porque negar que la ay, es inposible, porque vemos aquellos a que animados l'hamamos, hazer ciertas obras en un tempo, las quales, en otro tienpo no pueden hazer después y esto es claro indicio que algo avía en ellos por donde podían hazer esta obra antes y después no. Y este medio que en ellos avía lhamaron alma.

Por tanto dizir que ay alma es muy fácil y dificillícimo dizir que cosa sea y principalmente se hizo difícil a los que precedieron a Aristótilis porque ineraron la arte de difinir las cosas. Pero ansí a aquellos naturales como a Aristótiles y a todos los otros que después vinieron, fue esto muy difícil por causa de la misma alma en sí. Que es muy rezio falhar un vocáculo común que sea género ansí alma umana, como a la de los brutos y a la de las plantas y después la diferencia que ay de la una a la otra.

Aquello en que todos los antigos concordaron es que toda causa animada tiene movimiento y sentido y en esto difire de la cosa no animada. Tomando, pues, esto por fundamiento, cada uno como mejor se atrivió osó meter la mano en la difinición de la alma, pensando todos que la cosa que se mueve, ella misma es movida, de modo que no ay cosa que mueva sin ser movida. Contra lo determinado en el octavo de los phísicos. Sus opiniones recitaremos según Artistótiles rifire en el primero de los físicos ${ }^{19}$.

Lo que sigue es una vasta obra de erudición en que, efectivamente, vienen recogidos los nombres y las opiniones de Los más auténticos y antigos philósofos que sobre la alma escrivieron, de los filósofos y poetas griegos como Tales de Mileto, Demócrito, Pitágoras, Leucipo de Mileto, Arquelao, Anaxágoras, Heráclito, Diógenes de Sínope, Alcmeón de Crotona, Parménides, Empédocles, Pericles, Filipón, Eurípides, Platón, Xenócrates, naturalmente Aristóteles, Epicuro, Plotino, Alejandro de Afrodisias y Simplicio. Siguen las posiciones de los escritores y filósofos romanos tales como Virgilio, Cicerón y Séneca. Los comentaristas árabes tales Al-Farabi, Abubacar (Al-Razi), Averroes y Avicena ocupan un lugar más modesto. El pensamiento cristiano está representado por San Agustín. Tres son los filósofos del Quinientos citados: Guillaume Budé,

\footnotetext{
${ }^{19}$ Opiniones sacadas, ed. NovoA, pág. 5.
} 
Johannes Reuchlin y Girolamo Fracastoro. Tras una exposición de las posiciones presentadas hay un folio que contiene un sumario de veintiuna definiciones del alma ${ }^{20}$.

Las tres fuentes principales son el Timeo de Platón, la Física y la De anima de Aristóteles. En un lugar cita textualmente la Eneida de Virgilio, ofreciendo una traducción en prosa de unos versos del sexto libro del poema épico ${ }^{21}$, las Disputaciones Tusculanas de Cicerón, el Fedro y las Leyes de Platón.

Las Opiniones son obra de un autor imbuido de humanismo y que muestra profundo conocimiento del patrimonio intelectual del mundo antiguo. Son los pensadores griegos y romanos los que mayoritariamente dominan el texto, ocupando dieciséis páginas, mientras que dedica tan sólo dos a los comentadores árabes de la obra de Aristóteles. En cuanto a sus coetáneos, dos aparecen de manera pasajera, mientras que uno presenta la última definición del alma expuesta por Afia: Girolamo Fracastoro, humanista, poeta y médico veronés, autor del célebre poema Syphilis sive morbus gallicus libri tres (Verona 1530) y del famoso tratado médico De contagione et contagiosis morbis et curatione (Venecia 1546). Fracastoro había sido discípulo en Padua del filósofo renacentista Pietro Pomponazzi y amigo del literato veneciano Pietro Bembo:

Fracastoro, docto en muchas sciencias, se espanta de los que ponen el entendimiento agente apartado. Yo nunqua lo creeré aunque grandes barones lo ponen ansí que la vegetativa y la sensitiva quedan quanto a la sustancia y no quanto a la obra. Pero la entelectiva queda, quanto a la sustancia y la obra, porque sienpre entiende después de apartada, por tanto, esta se dize propiamente quedar porque ella sola queda entendiendo en auto, sin vegetar ni sentir ni tener poder para ello, sino milagrosamente y ansí como de la materia y de la forma se haze un cuerpo natural y todas las obras deste tal cuerpo procedendo la forma, como natureza autiva de la materia como pasiva, las quales materia y forma tienen diversas essencias y una de seer a la otra. Ansí el entendimiento se conpone del posible y del agente que son potencia y auto y hazen una sóla alma y una sóla obra que es el entender y lo que uno recibe haze el otro en auto y no es el mismo hazedor y padecedor un mismo auto y las cosas que diferen en razón y no en el seer como racional y risible es por causa de diversas obras y potencias para ellas como poder razonar y poder reir no como aquí entendimiento posible y entendimiento agente. Se dizen por causa de una sóla obra que es entender uno recibe y otro haze como el sol que da lustro al aire, por donde recibe los colores y él tiene potencia para los recibir. Ansí el entendimiento

\footnotetext{
${ }^{20}$ Opiniones sacadas, ed. NovoA, págs. 19-20.

${ }^{21}$ Versos 724-739 del libro VI de la Eneida; cf. pág. 9 de nuestra edición.
} 
agente, que es puro auto de nuestra alma, da otro más excelente lustro al entendimiento posible con que recibe las essencias de todas las cosas. Por tanto, se enganharon los antigos, pensando que nuestra alma era conpuesta de los elementos de todas las cosas, como si uviese menester que el espeio tuviese en sí la imagen de todas las cosas que en él se han de apresentar.

La illustración y auto del entendimiento agente basta para alunbrar el posible y lo hazer entender con los primeros principios que tiene de los quales depende todo el saber y esta conposición destos dos entendimientos es de partes incorpóreas y no de partes materiales y corpóreas que no derroga alla cinplicidad y incorpóreidad de la alma la tal conposición de auto y potencia ${ }^{22}$.

Efectivamente, Fracastoro compuso en torno al año 1548 un diálogo filosófico sobre el alma, titulado Fracastorius sive de anima, publicado póstumamente en la edición de sus obras completas que apareció en Venecia (1555), junto con otros dos diálogos filosóficos ${ }^{23}$. Fracastoro sostiene que el alma tiene un movimiento autónomo que no depende del cuerpo y, de hecho, con la muerte, queda liberada de él ${ }^{24}$. El alma, como la materia, es eterna porque está en movimiento continuo y siempre en acto ${ }^{25}$. Según el pensador veronés, el alma puede

22 Opiniones sacadas, ed. NovoA, págs. 18-19.

23 Los otros dos se titulaban Naugerius sive de poetica, y Turrius sive de intellectione. Todos fueron publicados en Venecia en la editio princeps de 1555. Fracastorius está ambientado en el monte Baldo, cerca de Verona y tiene cinco interlocutores: Andrea Navagero, Giangiacomo Bardulone, los hermanos Giambattista y Raimondo della Torre y el mismo Fracastoro. Fue editado por el célebre humanista y hombre político veneciano Giambattista Ramusio.

24 «Ergo et anima suo corpori, dum vivit, alligata movetur, non ab eo, sed cum eo, quo expedit. Ipso vero e mortuo, relinquit et anima ipsum, non derilicta ab ea, cui alligatur, catena, quae illam movet placet motori primo, fines rerum omnium noscenti», G. FraCASTORO, L'anima: con testo a fronte, E. Peruzzi, ed. (Firenze 1999), cap. 39, 8-9, pág. 158.

25 «Si enim huis finis sit moveri ut quiescat, corruptibile id erit; si vero ut non quiescat, erit incorruptibile. Igitur propria intellectus operatio cum sit omnia fieri per intellectionem et semper perfici, sempre perfectum esse et nunquam quiescere, proculdubio idem de intellectu dicendum erit quod de materia: et utrunque incorruptibilem et aeternum esse. Quae vero de corde et nutritione dicebas, nihil nos oppugnat. Cor enim duos habet motus et utriusque finis est quiescere ac quiescit etiam quantum datur. Sed nova necessitas, extrinsecus veniens, facit ut non diu quiete illa frui possit; quare rursus movetur, unde videtur semper moveri. Non est autem hoc nisi per accidens, non per se. Nutritio vero et ipsa, quanquam sempre aliqua in parte fiat, finem tamen habet unaquaeque pars, ad quam fit aggeneratio, et quiescit. Quare in universum, Turri, verum est omne, quod ex natura movetur ut quiescat, corruptibile esse, et omne corruptibile moveri ut quiescat. Item omne, quod per se movetur ut non quiescat, incorrputibile esse, et omne incorruptibile, si movetur, moveri ut non quiescat. Quibus ita se habentibus, si natura intellectus consideratur, videbimus ipsun in genere illorum esse quae per se moventur ut non quiescat in aliquo eorum 
disfrutar de la facultad de la imaginación, incluso sin el cuerpo ${ }^{26}$. En su obra, Fracastoro se separa de su maestro Pomponazzi que, en su conocido y polémico libro De immortalitate animae (Bolonia 1516), optó por una interpretación materialista de Aristóteles, según la lectura de Alejandro de Afrodisias contra la de Averroes. Pomponazzi había sostenido que el alma humana precisaba del cuerpo para poder ejercer la facultad de la imaginación, lo contrario de lo que sostenía Fracastoro. Además, según Fracastoro el alma posee un tipo de conocimiento que es superior a la imaginación y es el que permite que el hombre conozca a Dios ${ }^{27}$.

Después de presentar la posición del pensador veronés, Afia pasa a presentar la suya. En sustancia, ésta parece coincidir con la de Fracastoro, pero sigue una referencia al libro de Génesis, en la que por primera, y única, vez se entrevé el judaísmo del autor:

Dizimos, por tanto, que la alma umana es sustancia incorpórea, divina, inmortal, que vegeta, siente mueve y entiende, quando informa el cuerpo y después que el cuerpo la pierde, entiende solamente.

Como después entiende, no es a nos declarado aquí.

Y porque la santíssima Lei declara todas las cosas ansí ellas poder ninguno annadir, quitar o mudar letra alguna y si alguno lo haze es por

quae acquiruntur. Acquari enim in omni motu aliquid nocesse est, sed ultra appetire consuevere quae per se moventur, ut moventur. Quare et incorruptibilem ponere intellectum debemus et parem habere cum materia conditionem», L'anima, cap. 20, 11-22, págs. 122-124. Fracastoro responde a Della Torre, que había afirmado que el movimiento perenne (rasgo, para Fracastoro, de la inmortalidad) se hallaba incluso en las partes del cuerpo humano que eran corruptibles, que parecería constituir una prueba contra la inmortalidad del alma. El veronés se enfrenta a la objeción de Della Torre, arguyendo que aquellas partes del cuerpo que parecen estar dotadas de la motricidad propia de la inmortalidad en realidad carecen de ella. Fracastoro se inspira en la posición aristotélica, abogando por la inmortalidad de la materia y del intelecto. Al igual que la materia, el intelecto carece de una forma definida, pero es capaz de convertirse en cualquier forma y en movimiento continuo.

26 «Fatemur enim et nos intelligere animum hic per receptionem phastasmatum, et quantum ad hanc operationem uti socio corpore; secundum se tamen abstractum esse, et corpore nullo pacto indigere», L'anima, cap. 44, 2, pág. 164.

${ }^{27}$ «Quod vero postremo quaerebas, utrum anima per se alium habeat intelligendi modum quam per species et simulachra rerum, dicendum arbitror coniunctuam corpori animam non habere aliam per se cognitionem quam per species, quanquam sint aliter putent, separatam vero superacquirere aliam nobiliorem, per eam gratiam qua Deum cognoscere pose datum est ipsi», L’anima, cap 47, 1-2, pág. 168. En su disputa con Della Torre, Fracastoro mantiene que mientras que el alma está vinculada al cuerpo, conoce las cosas per species, pero al separarse, tiene acceso a otro tipo de conocimiento más noble que proviene de la gracia de Dios 
falta de ingenho que no puede conprender, acabaremos con las palabras de la Lei, que son las primeras escritas de la alma y después dellas no ay otras que a ellas allegen y de las se podrá sacar ser esta difinición buena y verdadera.

Hagamos honbre a nuestra imagen y semeiansa y poco después dize, formó el sennor Dios al honbre de polvo de la tierra y espiró en su cara esprito de vida y fue honbre en alma de vida.

Entendimiento es la alma en quanto conprende el seer de las cosas y las saca de potencia. ${ }^{28}$

Curiosamente, en el manuscrito autógrafo conservado del Fracastorius, su autor concluye el diálogo con el mismo tono que Afia, invocando al conocimiento de Dios, no solamente como causa final del alma, sino, incluso también, como parte de su definición, aunque los últimos capítulos de la obra no llegaron a imprimirse, tal vez por motivos de censura ${ }^{29}$. Cabe preguntarse si el autor saloniciense tuvo a su alcance algún manuscrito de la obra, inspirándose en ella.

Con toda probabilidad Afia leyó los textos del Estagirita en la traducción hecha por Johannes Argyropulos, humanista griego refugiado en Occidente tras la caída de Constantinopla y que fue maestro en Florencia de Marsilio Ficino y de Angelo Policiano. La traducción latina del humanista griego se convirtió en la más difundida durante el Quinientos en Italia y por toda Europa. Es, además, posible que Afia la hubiera leído en una edición que salió en Basilea en 1538, reeditada en 1542 con un resumen de los contenidos de las obras hechas por Vives y

${ }^{28}$ Opiniones sacadas, ed. NovoA, pág. 19.

29 «His ergo a magno opere factis supererai homo solus, qui fieret, qui optatet ipsum Deum maximum et sequeretur potentiam illius ac sapientiam artificiumque omne universi; condita universi esset cognosciturus, culturs atque intellecturus ipsumque universum omne mente penetraturus, artes omnes inventurus, civitates conditurus ac leges constiturus, cui reliquia quae facta erant parerent. Homo ergo sequitur postremum artificium, in quo maxime patet auctor et sapientia providentiaque cognoscuntur et splendent, cuius gratia tota alia que facta sunt confecta fuere. Neque enima universum hoc factum est lapides et metalla et arbores et usus et figurae ut beate spectemus; sed hoc ipsum animal con nobis simile fieri neque videretur nunquam debemus. Et igitur illa natura animae animalibus similis celestis enata ut cognoscat efectum maioris datam animam quidem; et demum unquam ipsae naturae nostrae non posset convenire; set pro iustitia omnium, pro bonitate et pietate et pro potentia immortalem illi animam donare, qua semper vivat et beatitudinem consequi posset, quia hic erit finis maximus hominis», L'anima, cap. 40-44, pág. 190. Peruzzi sugiere que algunos pasajes acerca de la predestinación de posible sabor luterano pudieron haber sido causa de la omisión por un censo, ibid. págs. 78-79. El médico veronés concluye su obra insistiendo que de todas las creaturas de la naturaleza, solamente el hombre está dotado de alma, y que Dios se manifesta más perfectamente en él que en cualquier otro ser, siendo la vida eterna y la beatitud el fin último del ser humano. 
unos comentarios por parte de Melanchton, dos personajes que fueron mencionados, como hemos tenido ocasión de ver, en el diálogo de Amato Lusitano ${ }^{30}$. En 1541, Melanchton había editado las obras de Luciano de Samosata, y las de Eurípides en 1562, además del Tractatus de sphaera de Johannes Sacrobosco (Venecia 1534 y París 1551). Es, tal vez, mera especulación la suposición de que Afia hubiera conocido estas ediciones de los clásicos que son obra del humanista protestante. Lo cierto es que si nos hemos de fiar del diálogo de Lusitano, los nombres de Vives y Melanchton no le eran desconocidos, ni tampoco el mundo cultural del humanismo europeo, en que aquellos hombres se movían ${ }^{31}$.

Sorprende, tal vez, la omisión total de la escolástica medieval y, más aún, de la filosofía judía medieval. No se trata de una obra apologética o de tipo proselitista. En ningún momento el autor polemiza con las posiciones filosóficas desde el punto de vista de la religión judía o invocando el pensamiento judío. En el apéndice a un ensayo sobre Spinoza consagrado a los libros españoles del filósofo de origen portugués, Yosef $\mathrm{H}$. Yerushalmi ha puesto de relieve este rasgo de la obra, destacando la singularidad de las Opiniones dentro del contexto de la tratadística judía acerca del tema, escrita en los siglos XVI y XVII ${ }^{32}$. De hecho, tal como señala el estudioso norteamericano, a Afia le interesa poco la inmortalidad del alma, tema que provocó mucho debate en aquellos siglos, especialmente en el ambiente converso. La única alusión explícita a la fe mosaica es la definición final que, como hemos visto, resulta un tanto confusa. Yerushalmi ha sugerido, incluso, que podría tratarse de un añadido artificial ${ }^{33}$.

Efectivamente, estamos ante una obra muy distinta de la tratadística en lengua española y portuguesa dirigida a los conversos, publicada en Ferrara y Ámsterdam,

${ }^{30}$ Aristotelis Stagiritae, philosophorum omnium facile principis, opera quae quidem extant omnia, latinitate vel iam olim, vel nunc recens a viris doctissimis donata et graecum ad exemplar diligentissime recognita. Accesserunt in singulos libros optimis ex autoribus argumenta, comentarii vice studiosis futura. Item Io. Lodovici Vivis Valentini, de libris Aristotelicis censura, nunc recens et nata et edita. Ad haec. De vita Aristotelis, de que genere philosophiae, ac scriptis eiusdem, commentatio doctissima per Philippum Melanchthonem. Basileae M.D.XXXVIII.

${ }^{31}$ La relación intelectual y cultural de Amato Lusitano con el mundo intelectual y científico del siglo XVI ha sido recientemente tratada en E. GUTWIRTH, «Amatus Lusitanus and the Location of Sixteenth-Century Cultures», en Cultural Intermediaries. Jewish Intellectuals in Early Modern Italy, eds. D. B. Ruderman \& G. Veltri, (Philadelphia 2004), págs. 216-238.

32 Y. H. Yerushalmi, «Propos de Spinoza sur la survivance du peuple juif suivi d'un appendice: l'Espagne et l'espagnol dans la bibliothèque de Spinoza», en Sefardica. Essai sur l'histoire des juifs, des marranes et des nouveaux-chrétiens d'origine hispano-portugaise (Paris 1998), págs. 175-233: 224.

33 Yerushalmi, «Propos de Spinoza», pág. 225. 
de obras como Consolação às tribulações de Israel, de Usque (1555); Nomología o discursos legales (1629), de Aboba; Conciliador (1632) y Esperanza de Israel (1657), de Menassé ben Israel; y Excelencia de los Hebreos (1679), de Cardoso. No hay, de parte del autor, ningún intento por convencer al lector de la validez del judaísmo o para atraerlo a la práctica normal de la fe judía. Aparte de la alusión pasajera a Génesis, el libro podía haber sido escrito por un cristiano y refleja la formación humanística de cualquier europeo culto del siglo XVI, sobre todo en ámbito médico, formado en las universidades europeas. Afia, como Amato Lusitano, pertenecía a aquella clase especial de médicos conversos, formados en un entorno cristiano, que constituyen una suerte de élite intelectual dentro de las incipientes comunidades sefardíes, aportando sus conocimientos y su particular comprensión de la fe judía ${ }^{34}$. Las Opiniones son un producto de aquel ambiente culto salonicense de los médicos conversos del siglo dieciséis, formados en Europa pero que optaron por volver a la fe de sus padres en aquella ciudad denominada por Usque «verdadeira madre do judesmo», en la cual la cultura humanística se expresaba en hebreo, castellano y latín ${ }^{35}$.

El contacto de Afia con la cultura europea e ibérica queda reflejado en la lengua del texto. El médico judío decide escribir en castellano, lengua que se convirtió desde la llegada de las primeras oleadas de los judíos ibéricos en la lingua franca de las comunidades sefardíes levantinas. El castellano de las Opiniones está aún bastante cercano a la lengua imperante en España. No apreciamos en él los rasgos de la incipiente koiné judeo-española que se consolidó a finales del

${ }^{34}$ Sobre la que llama la atención D. B. RudERMAN: «...there is sufficient evidence to suggest that the intrusion of a relatively large community of medical professionals with a substantial education in medicine and the natural sciences did inject a new and important cultural element into the Jewish communities with which they affiliated. Specifically, these physicians of Spanish and Portuguese origin found a common professional and cultural agenda with other Jewish graduates of medical schools in Italy and elswhere in Europe, creating a kind of informal medical and scientific fellowship among Jews, and projecting themselves as a kind of intellectual and cultural elite within their own communities. They helped to define a Jewish cultural identity along strictly secular and professional lines. Several of them even contributed to discussions of the nature of religious belief and epistemological uncertainty, even applying their own rational and naturalistic sensibilities to a radical rereading of the biblical text and the Jewish religious tradition. But most significantly, despite their often limited exposure to Jewish learning and religious observance, their notions of the Jewish self in relation to the Christian other that most had repudiated were profoundly fused with their professional identities as medical writers and clinicians», cf. su Jewish Thought and Scientific Discovery in Early Modern Europe, (New Haven 1995), pág. 56.

${ }^{35}$ Cf. Consolação às tribulações de Israel. Edição de Ferrara, 1553, com estudos introdutórios de Y. H. Yerushalmi e J. V. de Pina Martins (Lisboa 1989), f. ${ }^{\circ}$ CCXIII. 
siglo XVI y comienzos del XVII en los territorios del Imperio Otomano ${ }^{36}$, y es comparable a otra gran obra de libre creación del siglo XVI escrita en Levante, la Crónica de los reyes otomanos de Moisés Almosnino.

La vinculación de Afia con la cultura europea del momento se hace patente, además, en las mismas circunstancias de la producción del volumen en el que se incluye su obra: la traducción de los Diálogos de amor de León Hebreo, que, de hecho, ocupa la mayor parte del libro ${ }^{37}$. Dicha traducción ha sido atribuida a Guedalyá Yaḥyá, a quien algunos estudiosos han identificado con Guedalyá b. Mošé b. Yaḥyá, médico perteneciente a una prestigiosa familia judía portuguesa, mecenas de la vida cultural en Salónica durante la segunda mitad del siglo XVI. Fue además un conocido traductor de obras filosóficas del latín al hebreo, entre ellas, de san Alberto Magno. Guedalyá b. Yahyá habría sido el último huésped de Amato Lusitano, al que el humanista portugués dedicó su séptima Centuria, y al que denomina «vir sapiens et generose»y y en cuya casa murió en 1568 , víctima de la peste ${ }^{38}$. Fue un benefactor de la vida cultural en Salónica, ayudando a crear y sostener un nutrido círculo poético que se reunía en su casa ${ }^{39}$.

La inclusión de las Opiniones junto a los Diálogos de amor no podía ser casual. La obra de León Hebreo estaba también imbuida por la cultura humanística del Quinientos, y se pueden ver en ella los destellos del neoplatonismo florentino. Hay en ella sendas alusiones a la tradición judía pero, no estaba dirigida a lectores específicamente judíos. Además, fue una opinión bastante difundida durante el siglo XVI que su autor había abrazado el cristianismo ${ }^{40}$.

${ }^{36}$ L. Minervini, «La formación de la koiné judeo-española en el siglo XVI», Revue de Linguistique Romane 66 (2002), págs. 497-512.

37 Los Diálogos de amor de Mestre León Albarbanel... De nuevo traduzidos en lengua castellana... Con privilegio della Illustríssima Senoria. En Venetia... MDLXVIII, fols 1-115v. Sobre esta traducción, véanse mis «Consideraciones sobre una versión aljamiada de los Diálogos de amor de León Hebreo», Sef 65 (2005), págs. 103-126; y Los Diálogos de amor de León Hebreo en el marco sociocultural sefardí del siglo XVI (Lisboa 2006).

38 «Centuriam componerem, villico eam tibi dicandam constitui, Guedelia Yahia, vir sapiens et generose, multis de causis: prima, quia sapiense cum sis. Et concionatur egregius ac acri quodam ingenio praeditus longe iudiciorum magnus haberis existimator: quibus facile haec et huius generis alia, quanti sint valoris et arti medicae adiumentum praestare possint, diiudicabis»», cf. Lusitani, Curationum medicinalium. Centuria Septima, fols. 6-7. La noticia de la muerte de Lusitano en casa de Yahyá aparece en Nehama, Histoire des israélites de Salonique, pág. 177.

39 C. Rотн le dedica una entrada («Guedeliah ben Tam ibn Yahya») en la Encyclopedia Judaica 8 (Jerusalem 1971), col. 1210, mientras que Yerushalmi, «Propos de Spinoza», pág. 339, lo cita como «Guedeliah b. Moshe b. Yahya».

40 Esta opinión fue especialmente reforzada por la portada de dos ediciones venecianas de los Diálogos que declaraban que su autor se había convertido al cristianismo: Dialoghi di amore, 
Publicados en italiano, los Diálogos gozaron de enorme popularidad en el Quinientos, siendo reeditados al menos nueve veces, y traducidos al castellano, francés y latín.

El volumen llevado a la imprenta por Guedalyá b. Yaḥyá y compuesto por un tipógrafo desconocido, fue publicado con el aparente beneplácito de las autoridades venecianas ${ }^{41}$. Tres décadas después, en 1598, el libro apareció de nuevo en lo que se anunció como una nueva edición, pero que en realidad era la misma que la de 1568 con un simple cambio de portada ${ }^{42}$. En su dedicatoria a Felipe II, Guedalyá b. Yahyá demuestra que, pese a la distancia física e ideológica, por su empleo de la lengua castellana y su reconocimiento de un patrimonio cultural que aún les pertenece, los sefardíes se sienten vínculados todavía a la Monarquía Hispánica. Mediante su edición y dedicatoria, hemos de suponer que Guedaliá b. Yahyá sinceramente deseaba ver su libro circular en los territorios bajo dominio de la Monarquía Hispánica. No podía dejar de considerar como potenciales lectores del libro a aquellos correligionarios que vivían, bajo apariencia cristiana, en los Países Bajos, España y Portugal. Su decisión de incluir la obra de Afia no era seguramente casual. Escrita en castellano, no es una obra de filosofía judía, pero sí está escrita por un judío, en la que se proclama la verdad de la fe judía. En su exilio levantino, el interlocutor natural de Afia sigue siendo el mundo cristiano, del que el autor era producto.

Pese a la dedicatoria, el libro no parece haber circulado demasiado en España. No entró a formar parte de la biblioteca personal de Felipe II en El Escorial, y las únicas noticias de su presencia en España durante el periodo inmediatamente posterior provienen de una requisa de libros prohibidos en 1634 en Murcia, puesto que la edición de los Diálogos de amor de 1568 había sido condenada por el Indice de Zapata en $1632{ }^{43}$. Donde sí parece haber gozado de fortuna fue en Ámsterdam, y, de hecho, el volumen entra en la biblioteca personal de Spinoza. Yerushalmi ha especulado que el opúsculo podía haber influido en el pensador, sobre todo en sus años de formación, a través del cual hubiera tomado un primer contacto con la especulación filosófica acerca del alma en el pensamiento clásico, árabe, cristiano y renacentista ${ }^{44}$. Esa presen-

composti per Leone Medico, di natione Hebreo, et dipoi fatto Christiano. Aldus M.D.XLV; Dialoghi di amore, composti per Leone Medico Hebreo. Aldi Filii. In Venegia, M.D.XLIX.

41 Véase NovoA, Los Diálogos de amor de León Hebreo, págs. 233-240.

${ }^{42}$ NovoA, Los Diálogos de amor de León Hebreo, págs. 279-281

43 A. MárQuez, Literatura e inquisición en España (Madrid 1984), pág. 237.

${ }^{44}$ Yerushalmi, «Propos de Spinoza», pág. 226. 
cia del libro en la biblioteca de Spinoza muestra que el texto de Afia circuló aún durante el siglo XVII.

Las Opiniones sacadas de los más antigos philósofos que sobre la alma escrivieron constituyen una muestra sin precedentes de aquel mundo sefardí levantino en lo que fue, tal vez, su momento de mayor ebullición, cuando todavía acudían nuevos miembros procedentes de la Península Ibérica, para los que el refugio en la «madre do judesmo» significaba, tal vez en el sentido más amplio, abrazar también la civilización europea en su totalidad.

Recibido: 20/02/2006

Aceptado: 01/06/2007 
